\title{
Effect of Storage on the Sensory Attributes of Probiotic Carbonated Beverage from Ber Fruit (Ziziphus mauritiana)
}

\author{
Zahara Ali Shams ${ }^{1 *}$ and Nikita Wadhawan ${ }^{2}$ \\ ${ }^{1}$ College of Community and Applied Sciences, Maharana Pratap University of Agriculture \\ and Technology, Udaipur, Rajasthan, India \\ ${ }^{2}$ CDFST, Maharana Pratap University of Agriculture and Technology, Udaipur, \\ Rajasthan, India \\ *Corresponding author
}

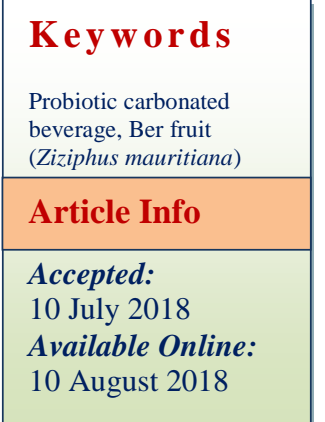

\section{Introduction}

Fruits, which neither is grown commercially nor traded widely, are termed as underutilized fruit crops. Most of the indigenous fruits are underutilized. There are quite a large number of indigenous and underutilized fruit crops, which are being used by the local inhabitants. In fact, for people living in villages, these underutilized fruits are the only source of protective food to meet their vitamins and minerals requirements in their poor diet. Their cultivation is very restricted and they grow
Investigation was conducted to develop Ber (Ziziphus mauritiana) fruit based probiotic carbonated ready to drink beverage. Bacterial strain of Lactobacillus acidophilus was used to prepare the beverage. Total four variables were developed containing different concentration of bacterial culture i.e., $0 \%, 1 \%, 1.5 \%$ and $2 \%$ of inoculation and labelled as $\mathrm{T} 1, \mathrm{~T} 2, \mathrm{~T} 3$ and $\mathrm{T} 4$; respectively. Carbonation was done by mixing chilled carbonated water at 60 psi pressure, followed by sealing. The beverage was free from any artificial preservative. The freshly developed variables were examined for sensory characteristics. The beverage was kept at $4^{0} \mathrm{C}$ temperature for 45 days and was evaluated for sensory scores on every $15^{\text {th }}$ day. The drink scored above 7.0 for overall acceptability on a nine point hedonic scale rating and showed the positive response of the consumer. A significant decline was recorded in all sensory attributes and mean overall acceptability was reduced to $6.07 \pm 0.99$. The initial value of total viable count of L. acidophilus were $15.8 \times 10^{7}, 20 \mathrm{X}$ $10^{7}$ and $22.9 \times 10^{7} \mathrm{cfu} / \mathrm{ml}$ for $\mathrm{T} 2, \mathrm{~T} 3$ and $\mathrm{T} 4$. 
tolerate a range of soil types including those exhibiting moderate arid salinity. It gives good production even without irrigation and can be grown as rainfed crop at high temperature in semi-arid and arid regions. The trees can therefore, give assured income even under marginal growing conditions and provide nutritious food at very low cost. It is rich in ascorbic acid and contain fairly good amount of vitamin $\mathrm{A}$ and $\mathrm{B}$, minerals like calcium, phosphorus and iron. The ascorbic acid content of ber fruit is higher than the orange (Kavitha, 2011).

The genus Ziziphus comprises about 40 species distributed throughout the tropical and subtropical regions of the world. The major production area in India is Maharashtra, Gujarat, Madhya Pradesh, Punjab, Haryana, Rajasthan, Bihar, Karnataka, Andhra Pradesh, Tamil Nadu, West Bengal and Assam.

India ranks second among ber growing countries in the world after China, occupying approximately one lakh hectare area (Bal, 2016). Among the important cultivars, eleven are described in the encyclopaedic Wealth of India: 'Banarasi (or Banarsi) Pewandi', 'Dandan', 'Kaithli' ('Patham'), 'Muria Mahrara', 'Narikelee', 'Nazuk', 'Sanauri 1', 'Sanauri 5', 'Thornless' and 'Umran' ('Umri'). The skin of most is smooth and greenish-yellow to yellow (Pawar et al., 2012).

The production of ber is confined to a particular season leading to surplus production and glut in the market. The shelf-life of ber is extremely short, hardly 2 to 4 days at ambient temperature conditions, thus early perishability of the fruit possesses a problem and thus needs quick disposal or converted into food products with keeping quality. The development of various value added products greatly helps to minimize the post-harvest losses as well as make it available throughout the year for its nutritive value.
Probiotics can be defined as microbial cells that have a beneficial effect on the health and wellbeing of the host. Since the gastrointestinal mucosa is the surface of contact with probiotics, it seems evident that the first effects of probiotics relate to digestive function.

A brief review of the literature indicates that probiotics have very few effects on the main physiological functions of the gastrointestinal tract, which are digestion, absorption and propulsion. Fruits and vegetables offer an alternative for the production of probiotic foods due to their large distribution and nutritive value. Lactic acid fermentation can help to improve the safety, shelf life, and nutritional and sensory properties of vegetable.

The vegetable juice proved to be a suitable media for the production of a fermented probiotic drink and can serve as a healthy beverage for vegetarians, particularly diabetics. However, very recently Ebel et al., (2014) have reviewed the impact of probiotics on the risk factors of cardiovascular diseases including its impact on hypercholesterolemia. In 2015, Vijayendra and Halami also reviewed the fermented fruits and vegetables of Asian region as a potential source of probiotic cultures and its health benefits.

Strains of several Lactobacillus species have been proven to exert a range of health promoting activities such as immunomodulation, enhancement of resistance against pathogens and reduction of blood cholesterol levels and are used as probiotics. Therefore, beverages are the next food category where the healthy bacteria will make their mark and likely candidates are chilled fruit juices, bottled water and vegetable juices. Therefore, considering the above mentioned facts cereals, fruits and vegetable may be potential substrates, where 
the healthy probiotic bacteria will make their mark, both in the developing and the developed countries (Sharma and Mishra, 2013). Inclusion of fruit juice in the soft drinks not only imparts characteristic colour and flavour but also provides some nutrients. The demand for soft drinks is increasing every year.

This trend can be exploited by developing nutrient enriched carbonated fruit based beverages. These beverages can be well marketed at recreational places such as college cantens, cinema hall, cafetarias, public places or food court of malls. The growing health consciousness of consumers has made the industry to introduce a variety of beverages. The fruit based carbonated beverages can replace the promiscuous consumption of artificial soft drinks. The study is conducted with the following objectives:

To evaluate the sensory attributes of probiotic carbonated RTS beverage.

To study the changes occurred in sensory attributes due to 45 days of storage period

\section{Materials and Methods}

Development and Standardization of ber fruit based probiotic carbonated RTS beverage: Hot process was used to extract pulp and juice of ber fruit, followed by addition of sugar and citric acid to prepare syrup (concentrate), suggested by Arora et al., 2011. Prepared syrup samples were fermented by inoculating L. acidophilus culture at $0 \%, 1 \%, 1.5 \%$ and $2 \%$ which were incubated at $37{ }^{0} \mathrm{C}$ for 48 hours. The concentrates were filled in $250 \mathrm{ml}$ pre sterilized PET bottles at the rate of $80 \mathrm{ml}$ and then chilled carbonated water was poured in each bottle leaving head space of 2-3 cms and sealed. The prepared drink was free of any kind of artificial preservatives and kept under refrigration $\left(4{ }^{0} \mathrm{C}\right)$ for a period of 45 days.
Development and standardization of ber fruit based probiotic carbonatd RTS beverage

\section{Sensory evaluation}

Organoleptic or sensory evaluation refers to the evaluation of food product by sense organs. All the sense organs are used in the appraisal of food. The acceptance or rejection is based largely on the stimulus of sense organs of an individual. Therefore, the sensory qualities such as colour, flavour, tatse, appearance, mouth feel and overall acceptability were evaluated by semi-trained panel of judges for assessing the acceptability of the product (Ranganna, 1986). Score card was developed for evaluating the product for its qualities viz., colour, flavour, taste, appearance and overall acceptability. Nine point Hedonic Scale given by Jones, Peryam and Thurstone (1995) was used for rating of sensory attributes of each sensory trait and indicating their preferences. The score so observed were averaged for all the characters and for overall acceptability.

\section{Shelf life assessment of probiotic carbonated RTS beverage}

The developed probiotic carbonated RTS beverage samples were stored in refrigerator for a period of 45 days. The stored samples were evaluated at $0^{\text {th }}$ day and at every 15 days interval for organoleptic parameters (Table 1).

\section{Results and Discussion}

Sensory evaluation: Sensory scores as assigned by panel members for individual sensory attributes and overall acceptability were averaged out and presented in the Table 2. The data clearly portrays the fact that the samples T1, T2 and T3 have obtained mean score above 8.0 on the scale for sensory evaluation. This proved that the T1, T2 and T3 
were liked got extreme likeness by the consumers. Even the T4 sample also scored 7.82 mean values on the hedonic scale out of 9.0 rating that showed moderate likeness. Thus, it is evident from the scores that all samples were accepted well by the consumers.

Effect of storage period on the sensory characteristics of probiotic carbonated RTS are as: The sensory quality of fruit based probiotic juice plays a vital role in attracting consumers to purchase the product. Consumer judges juice quality on the basis of its sensory parameters such as color, taste and flavour etc. Sensory evaluation was carried out to evaluate fresh as well as stored sample after $0,15,30$ and 45 days (Table 3).

\section{Appearance}

Table 4 shows the mean preference rating of judges on the basis of the appearance of the samples. It is clearly found that the highest rating was given to the $\mathrm{T} 1$ and $\mathrm{T} 2$ samples as Mean $8.90 \pm 0.30$. Amongst all treatments the scores of T1, T2, T3 and T4 varied significantly from 8.9 to 8.68 . The scores obtained by the RTS depicted that the appearance of the product was highly liked by the consumers.

During storage period the changes among the given ratings was also found significant as shown in the Table 5. Till $30^{\text {th }}$ day the mean values were same but as the $45^{\text {th }}$ day approached, significant change was calculated at $\mathrm{p}<0.001$.

Although, it was clear that there is significant difference between the appearance of beverage and various treatment as well as appearance rating and shelf life, but in both cases the mean rating is almost or more than 8.5. This shows that the all treated samples fresh as well as refrigerated high sensory scores for appearance attribute.

\section{Colour}

Amongst the four treatments, T1 got highest mean rating for colour attribute followed by T2, T4 and T3. It was found that colour of four treatments varied significantly at $\mathrm{p}<$ 0.001. Sensory scores obtained by all four treatments are satisfactory and acceptable from consumer's point of view.

As the interaction between storage period and colour attribute were evaluated again the changes were found out to be significant ( $\mathrm{p}<$ 0.001 ) with the highest mean value given to the freshly prepared beverage samples. Thus, it was found that though there was gradual deterioration in the colour attribute of samples as shelf life proceeded, yet the mean value colour scores was above eight and very much liked by the consumers.

\section{Flavour}

Flavour of drink is described as a combination of aroma and taste. The sample T1 scored the highest mean rating on the flavour attribute as clearly shown in the table 6 . The test score is higher for the controlled group and then decreases with increase in the inoculation percentage. The scores of T1, T2, T3 and T4 varied significantly $(\mathrm{p}<0.001)$ from 7.83 to 6.04. T1 scored highest for the flavour attribute and the least was obtained by $\mathrm{T} 4$ with the highest inoculation percent. As the ratings or all samples are above 6 it is clear that the developed product has higher flavour attribute.

Results suggested that the interaction of flavour attribute and refrigeration period a gradual declined from $0^{\text {th }}$ day to $45^{\text {th }}$ day. There is clear deterioration as storage period proceeded. Yet, the scores are on higher side throughout the storage period it is clear that the flavour of products retained enough throughout the refrigeration period and product can be stored at $4^{\circ}$ centigrade for 45 days (Table 7). 
Fig.1 Development and standardization of ber fruit based probiotic carbonated RTS beverage

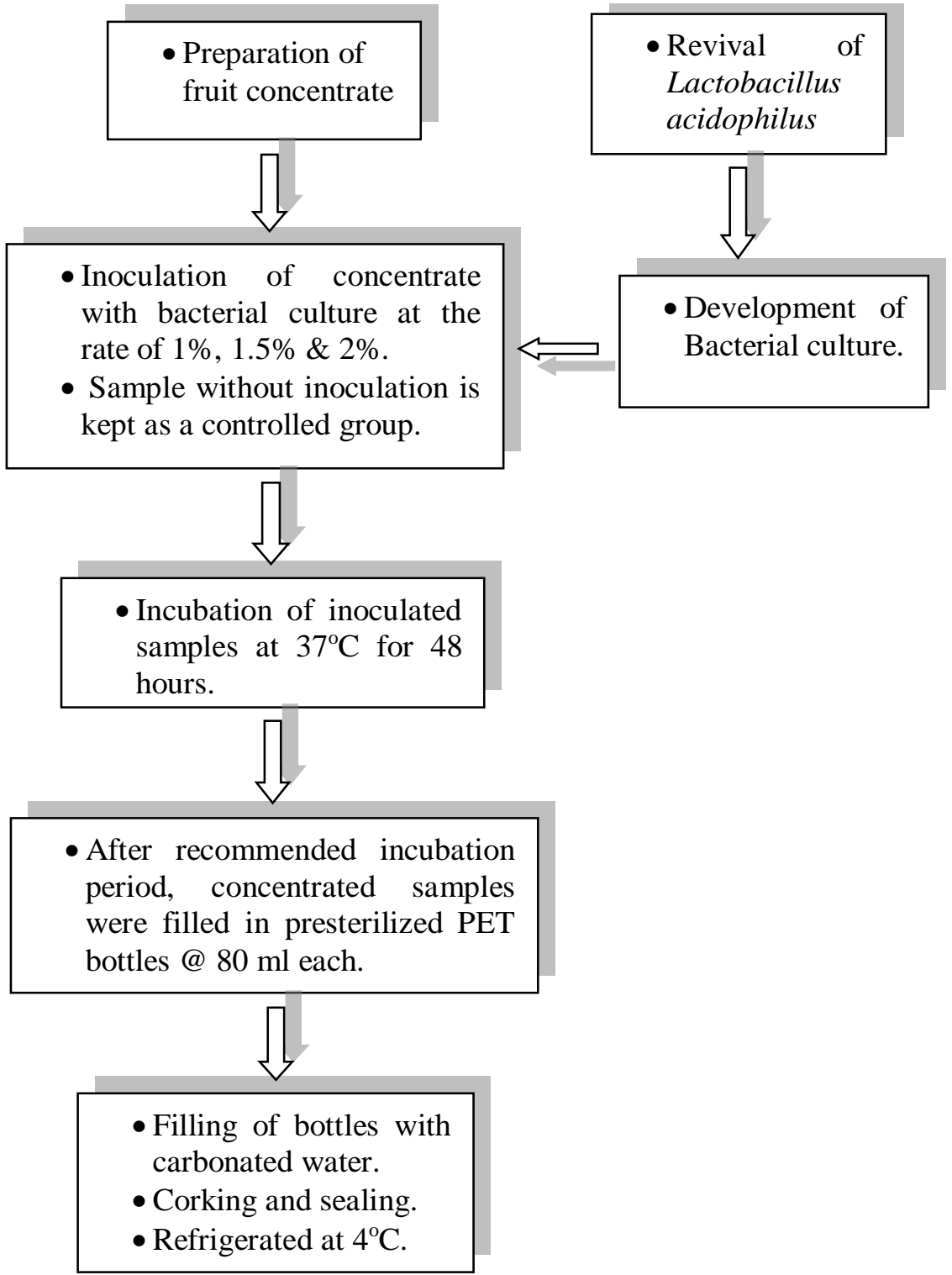

Table.1 Organoleptic scores of different treatments of freshly prepared

Probiotic carbonated RTS

\begin{tabular}{|c|c|c|c|c|c|c|c|}
\hline Sample & \multicolumn{9}{|c|}{ Sensory attributes } & Mean \\
\hline & Colour & Appearance & Taste & Flavour & Mouthfeel & $\begin{array}{l}\text { Overall } \\
\text { acceptability }\end{array}$ & \\
\hline T1 & 8.9 & 8.9 & 8.9 & 8.8 & 8.9 & 8.06 & 8.74 \\
\hline T2 & 8.96 & 8.9 & 8.9 & 8.8 & 8.0 & 7.06 & 8.43 \\
\hline T3 & 8.86 & 8.9 & 8.0 & 7.0 & 8.0 & 8.0 & 8.12 \\
\hline T4 & 8.96 & 8.9 & 7.06 & 8.0 & 7.0 & 7.0 & 7.82 \\
\hline Mean & 8.92 & 8.9 & 8.21 & 8.15 & 7.97 & 7.53 & \\
\hline
\end{tabular}


Table.2 Appearance of the probiotic carbonated RTD

\begin{tabular}{|c|c|c|c|c|c|}
\hline Treatment & $\mathbf{N}$ & Mean & F & Df & Result \\
\hline T1 & 120 & $8.90 \pm 0.30$ & 8.151 & 3,476 & $* * *(\mathrm{p}<$ \\
\hline T2 & 120 & $8.90 \pm 0.30$ & & & $0.001)$ \\
\hline T3 & 120 & $8.68 \pm 0.66$ & & & \\
\hline T4 & 120 & $8.68 \pm 0.61$ & & & \\
\hline
\end{tabular}

Table.3 Effect of storage on appearance of probiotic carbonated RTD

\begin{tabular}{|l|l|l|l|l|l|} 
Day & N & Mean & F & df & Result \\
\hline 0 Day & 120 & $8.90 \pm 0.30$ & 27.254 & 3,476 & $* * *(p<$ \\
\hline 15th Day & 120 & $8.90 \pm 0.30$ & & & $0.001)$ \\
\hline 30th Day & 120 & $8.90 \pm 0.30$ & & & \\
\hline 45th Day & 120 & $.45 \quad 0.79$ & & & \\
\hline
\end{tabular}

Table.4 Sensory scores on the basis of colour attribute

\begin{tabular}{|c|c|c|c|c|c|}
\hline Treatment & $\mathbf{N}$ & Mean \pm SD & $\mathbf{F}$ & df & Result \\
\hline $\mathrm{T} 1$ & 120 & $8.90 \pm 0.30$ & \multirow{4}{*}{$\begin{array}{l}24.34 \\
5\end{array}$} & \multirow[t]{4}{*}{3,476} & \multirow{4}{*}{$\begin{array}{l}* * * * \\
0.001)\end{array}$} \\
\hline $\mathrm{T} 2$ & 120 & $8.89 \pm 0.31$ & & & \\
\hline $\mathrm{T} 3$ & 120 & $8.40 \pm 0.90$ & & & \\
\hline $\mathrm{T} 4$ & 120 & $8.47 \pm 0.65$ & & & \\
\hline
\end{tabular}

Table.5 Effect of storage period on the Colour attribute

\begin{tabular}{|l|l|l|l|l|l|l|}
\hline Day & N & Mean \pm SD & F & df & Result & \\
\hline 0 Day & 120 & $8.93 \pm 0.26$ & 40.698 & 3,476 & $* * * \quad(p \quad<$ \\
\hline 15th Day & 120 & $8.88 \pm 0.32$ & & & $0.001)$ & \\
\hline 30th Day & 120 & $8.65 \pm 0.56$ & & & & \\
\hline 45th Day & 120 & $8.20 \pm 0.90$ & & &
\end{tabular}

Table.6 Sensory scores on the basis of flavor attribute

\begin{tabular}{|l|l|l|l|l|l|}
\hline Treatment & N & Mean \pm SD & F & df & Result \\
\hline T1 & 120 & $7.83 \pm 0.83$ & 55.502 & 3,476 & $(\mathrm{p}<0.001)$ \\
\hline T2 & 120 & $7.37 \pm 1.18$ & & & \\
\hline T3 & 120 & $6.45 \pm 0.79$ & & & \\
\hline T4 & 120 & $6.04 \pm 1.77$ & & & \\
\hline
\end{tabular}


Table.7 Effect of storage period on the flavor attribute

\begin{tabular}{|l|l|l|l|l|l|l|}
\hline Day & N & Mean \pm SD & F & df & Result \\
\hline 0 Day & 120 & $8.15 \pm 0.88$ & 118.153 & 3,476 & $* * * \quad(p$ & \\
\hline 15th Day & 120 & $7.38 \pm 0.75$ & & & $0.001)$ \\
\hline 30th Day & 120 & $6.39 \pm 1.23$ & & & \\
45th Day & 120 & $5.77 \pm 1.29$ & & & \\
\end{tabular}

Table.8 Sensory scores based on taste attribute

\begin{tabular}{|l|l|l|l|l|l|}
\hline Treatment & $\mathbf{N}$ & Mean \pm SD & F & df & Result \\
\hline T1 & 120 & $8.17 \pm 0.89$ & 64.811 & 3,476 & $* * *(p<0.001)$ \\
\hline T2 & 120 & $7.45 \pm 1.31$ & & & \\
\hline T3 & 120 & $6.71 \pm 1.15$ & & & \\
\hline T4 & 120 & $6.27 \pm 1.16$ & & & \\
\hline
\end{tabular}

Table.9 Effect of storage period on the taste attribute

\begin{tabular}{|l|l|l|l|l|l|}
\hline Day & N & Mean \pm SD & F & df & Result \\
\hline 0 Day & 120 & $8.23 \pm 0.91$ & 116.016 & 3,476 & $* * *(p<0.001)$ \\
\hline 15th Day & 120 & $7.69 \pm 0.97$ & & & \\
\hline 30th Day & 120 & $6.72 \pm 1.15$ & & & \\
\hline 45th Day & 120 & $5.96 \pm 1.06$ & & & \\
\hline
\end{tabular}

Table.10 Sensory scores n=based on mouthfeel attribute

\begin{tabular}{|l|l|l|l|l|l|}
\hline Treatment & N & Mean \pm SD & F & df & Result \\
\hline T1 & 120 & $8.01 \pm 1.24$ & 57.372 & 3,476 & $* * *(p<0.001)$ \\
\hline T2 & 120 & $7.03 \pm 0.90$ & & & \\
\hline T3 & 120 & $7.03 \pm 1.40$ & & & \\
\hline T4 & 120 & $6.01 \pm 1.13$ & & & \\
\hline
\end{tabular}

Table.11 Effect of storage period on the mouthfeel attribute

\begin{tabular}{|l|l|l|l|l|l|}
\hline Day & N & Mean \pm SD & F & df & Result \\
\hline 0 Day & 120 & $7.99 \pm 0.88$ & 121.265 & 3,476 & $* * *(p<0.001)$ \\
\hline 15th Day & 120 & $7.50 \pm 1.25$ & & & \\
\hline 30th Day & 120 & $7.00 \pm 1.00$ & & & \\
\hline 45th Day & 120 & $5.58 \pm 0.98$ & & & \\
\hline
\end{tabular}


Table.12 Sensory scores based on overall acceptability

\begin{tabular}{|l|l|l|l|l|l|l|} 
Treatment & N & Mean \pm SD & F & df & Result & \\
\hline T1 & 120 & $7.61 \pm 0.86$ & 50.299 & 3,476 & $* * * \quad(p \quad<$ \\
\hline T2 & 120 & $6.54 \pm 0.85$ & & & $0.001)$ & \\
\hline T3 & 120 & $7.30 \pm 1.05$ & & & & \\
\hline T4 & 120 & $6.25 \pm 1.13$ & & & & \\
\hline
\end{tabular}

Table.13 Effect of storage period on the overall acceptability

\begin{tabular}{|l|l|l|l|l|l|}
\hline Day & N & Mean \pm SD & F & df & Result \\
\hline 0 Day & 120 & $7.54 \pm 0.89$ & 74.436 & 3,476 & $* * *(p<0.001)$ \\
\hline 15th Day & 120 & $7.53 \pm 0.89$ & & & \\
\hline 30th Day & 120 & $6.57 \pm 0.95$ & & & \\
\hline 45th Day & 120 & $6.07 \pm 0.99$ & & & \\
\hline
\end{tabular}

Taste

As the samples were scored on the basis of their respective taste it was found out that all four treatments scored higher taste values that is above 6 on the scale of $1-9$. The T1 sample which has no inoculum scored the highest mean value as $8.17 \pm 0.89$, then $\mathrm{T} 2$, $\mathrm{T} 3$ and the least was scored by $\mathrm{T} 4$ with the highest percentage of inoculum.

The changes among the taste score of T1, T2, $\mathrm{T} 3$ and T4 found out significantly varied $(\mathrm{p}<$ 0.001 ) as shown in the Table 8.

Freshly prepared beverage scored the highest mean rating on the basis of taste attribute 8.23 \pm 0.91 and then a gradual decline in the taste scores can be seen as on $15^{\text {th }}$ day it was recorded as mean value $7.69 \pm 0.97$, on $30^{\text {th }}$ day $6.72 \pm 1.15$, and on $45^{\text {th }}$ day $5.96 \pm 1.06$. The variation among taste scores were analysed as significant at $0.1 \%$ of confidence level.

Though, it was clear that during storage in refrigerator deterioration in taste was observed, yet the scores were at higher side of the scale and showed the positive preference of judges (Table 9).

\section{Mouth feel}

It is a property of great importance for the sensory impression of many foods and it thus associated with the consumer acceptability. As it seems to be a complex property with several definitions suggested. The ISOstandard 'Sensory analysis-Vocabulary' (IS0 5492: 1992) defines mouthfeel as: "The tactile sensations perceived at the lining of the mouth, including the tongue, gums and teeth."

The sample $\mathrm{T} 1$ has again scored higher mean value on the basis of mouthfeel attribute followed by T2, T3 and least of T4, as given in the table 10. This showed that the sample with no inoculation has scored the highest rating and then the scores decreases slightly with the increase in the inoculation percentage as $1 \%$ and $1.5 \%$ inoculation obtained same mean value of 7.03 and the treatment T4 with $2 \%$ of inoculation scored 6.01 mean values. A significant variation is obtained among all treatments at $(\mathrm{p}<0.001)$.

The results obtained were above six and showed clearly the positive response to the attribute of the beverage and thus concluded the preference of judges for all four treatments (Table 11). 
Further, investigation on the interaction between storage period and mouthfeel suggested that the mean values are varied significantly as the storage time increased ( $p$ $<0.001$ ) from 7.99 on $0^{\text {th }}$ day, 7.50 on $15^{\text {th }}$ day, 7.00 on $30^{\text {th }}$ day and the least on the $45^{\text {th }}$ day as 5.58 (Table 11). Although there is significant decline in the mouthfeel scores, yet the scores were almost 8.00 for $0^{\text {th }}$ day and more than 7.00 for $15^{\text {th }}$ and $30^{\text {th }}$ day respectively; which speculated a promisingly positive response of judges towards the samples tested. Even on the last day of storage span the ratings were clearly above the 5.00 (Table 13), which showed the positive preference of judges.

\section{Overall acceptability}

The data regarding changes in overall acceptability score of carbonated beverage is presented in table 12. Consumer acceptability was evaluated for all fresh as well as refrigerated samples after $0,15,30$ and 45 days. Overall acceptability is based on the consumer acceptability

As storage period advanced there was continuous decrease in overall acceptability score. The mean overall acceptability score decreased from 7.54 to 6.07 as given in the table 13. The observed variations in the overall acceptability with the advance in the storage period were found out significantly different $(\mathrm{p}<0.001)$. It was well depicted in the figure 1 that there is very slight difference is observed in the mean values of T1 and T2 sample that means sample with no inoculation and $1 \%$ inoculation both are preferred more by the consumers. Samples with $1.5 \%$ and 2 $\%$ inoculation have obtained mean values as 6.57 and 6.07 respectively, which denote both have higher levels on preference scale.

The study of changes in the sensory attributes of probiotic carbonated RTS during 45 days of storage period, concluded that though there was decline in all the sensory characteristics, yet the product was found to be acceptable on the very last day of storage. Out of four treatments, $\mathrm{T} 1$ and $\mathrm{T} 3$ proved to be the best on the basis of scores obtained for overall acceptability on the $45^{\text {th }}$ day. Thus, it can be concluded that ber fruit based probiotic carbonated RTS are superior to commercial carbonated soft drinks. It contains beneficial microorganisms as well as carries the widely relished carbonated fizz. Moreover, the developed RTS beverage does not have any sort of chemical or artificial preservative which makes it as an organic drink devoid of any harmful and synthetic ingredient

\section{References}

AOAC. 2004. Association of Official Analytical Chemists. Official Methods of Analysis. Hortwitz, W (ed.), 20 ${ }^{\text {th }}$ ed, Washington, D.D. 1015p.

Arora, R.K., Azam-Ali, S., Clement, C.R., Haq, N., Hughes, A, Schreckenberg, K., Simons, A.J., and Smith, R.W. 2011. Fruits for the Future 2: Ber Ziziphus mauritiana Lam. - Field manual for Extension Workers. Crops for the Future, Darul Ehsan, Malaysia. pp: 21.

Bal, J.S. 2016. Development and production of Indian Jujube (Ber) in India. In proceedings of International Horticultural Congress on Horticulture: Sustaining Lives, Livelihoods and Landscapes): III International Jujube Symposium. On $16^{\text {th }}$ November 2016.

Davis, C. 2014. Enumeration of Probiotic Strains: Review of Culture-Dependent And Alternative Techniques to Quantify Viable Bacteria. Journal of Microbiological Methods. 103: 9-17.

Ebel, B., Lemetais, G., Beney, L., Cachon, R., Sokol, H., Langella, P. and Gervais, P. 2014. Impact of probiotics on risk factors for cardiovascular diseases. 
Critical Review of Food Science and Nutrition. 54(2):175-89.

ISO-standard ISO/TC34/SC12 1994. Sensory analysis-Vocabulary 5492: 1992. Retrieved from https://www. researchgate.net/publication/229616732 _What_is_mouthfeel_Sensoryrheological_relationships_in_instant_ho t_cocoa_drinks as on 18 June 2018.

Kavitha, S. 2011. Standardization and storage studies on value added products of Ber (Ziziphus mauritiana. Lamk.) cv. Gola. M.Sc. thesis submitted to Andhra Pradesh Horticultural University, Venkataramannagudem, Andhra Pradesh.

Pawar, A.B., Bhosale, A.B., Kadlag, A.D. and Tamboli, B.D. 2012. Nutritional Status of Local Ber (Ziziphus mauritiana L.)
Types from Solapur District, Scarcity Zone of Maharashtra. Indian Journal of Dryland Agriculture Research \& Development. 27(1): 101-104.

Ranganna, S. 1995. Handbook of Analysis and Quality Control for Fruit and Vegetable Products. Tata McGraw-Hill Education, Mysore, Karnataka. Pp. 2022.

Sharma, V. and Mishra, H.N., 2013. Fermentation of vegetable juice mixture by probiotic lactic acid bacteria. Nutrafoods. 12: 17-22.

Vijayendra SVN, Halami PM (2015) Fermented vegetables-health benefits. In: Tamang JP (ed) Fermented vegetables. CRC Taylor \& Francis Publisher, USA, Pp. 327-344.

\section{How to cite this article:}

Zahara Ali Shams and Nikita Wadhawan. 2018. Effect of Storage on the Sensory Attributes of Probiotic Carbonated Beverage from Ber Fruit (Ziziphus mauritiana). Int.J.Curr.Microbiol.App.Sci. 7(08): 1405-1414. doi: https://doi.org/10.20546/ijcmas.2018.708.161 